\title{
THE IMPACT OF BAROMETRIC VARIATIONS ON THE SEA LEVEL IN COASTAL AREAS USING GNSS REFLECTOMETRY
}

\author{
Théo Gravalon ${ }^{1,2}$ Lucia Seoane $^{1,2}$ José Darrozes $^{1,2}$ Guillaume Ramillien $^{1,3}$ \\ 1. Géosciences Environnement Toulouse (GET), France \\ 2. Université Paul Sabatier (UPS), France \\ 3. Centre National de la Recherche Scientifique (CNRS), France
}

\begin{abstract}
The Local Inverse Barometer (LIB) effect is a complex phenomenon which consists in the response in sea level surface variations to barometric changes. This contribution aims to study the evolution of the impact of this phenomenon on sea level in different sites in coastal areas. Four GNSS stations were used all over the world (Port-Tudy on Groix island (France), Tarifa in Spain, Fort-de-France on Martinique island (overseas France) and Lyttelton in New-Zealand) in order to retrieve coastal sea level height through SNR-based GNSS reflectometry. This sea level height estimates are then extensively compared to oceanic tides and surge effects due to pressure variations. The results show that the impact of the LIB effect on sea level is strongly dependent on the location but also on the spatial extension and timescales.
\end{abstract}

Index Terms- GNSS-R, inverse barometer, tides, coastal studies

\section{INTRODUCTION}

Oceans physics are driven by many different events. Some of them will have a direct impact on the sea level height (SLH). They range from the well-known astronomical tides to the local bathymetry passing by meteorological and climatic effects such as the Local Inverse Barometer (LIB). Different methods are available to estimate the SLH in different conditions. Tides gauges measurements are usually used to observe the SLH. However during the previous decades, some other techniques have been developed, such as satellite altimetry and GNSS reflectometry.

\subsection{The Local Inverse Barometer}

The Local Inverse Barometer (LIB) consists in the displacement of the sea surface in response to local barometric variations: if the local pressure decreases of $1 \mathrm{mbar}$, the local sea level height should increase of about $1 \mathrm{~cm}$ and inversely.

The response of the sea level surface to barometric variations was shown to be strongly related with the conditions of the considered site, its location and the timescale [1]. This response tends to decrease inversely with the latitude as the barometric variations themselves inversely decrease with latitude. Moreover, the response of the sea level surface is not an instantaneous phenomenon as the ocean takes time to reach a new equilibrium (of the order of one day) [2]. The response to the LIB effect was shown to increase as the barometric variation frequency decrease until a threshold of about $1 \mathrm{~cm} / \mathrm{mbar}$ [1]. This dynamic behavior is more significant in low latitude regions. Other phenomena such as waves, wind, etc. which can lead to significant surges tend to mask the effects of the LIB. Therefore in this study we have chosen sites where the LIB is dominant on the other effects of surges.

\subsection{Sea level measurements derived from GNSS-R}

The application of the GNSS-R for measuring SLH has been developed in the last two decades, allowing to achieve sea level altimetry in the coastal zone, where classic satellite altimetry faces several problems mainly due to pollution by the back radar signal of land surface at the ground-sea interface.

The GNSS-R measurements deliver a centimeter accuracy and different comparisons between the GNSS-R method results and tide-gauge records show high correlations [3] sometimes exceeding 0.9 [4].

Using astronomical tides models we can compute the residual signal by the difference between the sea level measurements and the theoretical value of these periodic tides. This residual can be defined as the subtidal sea level (SSL) and contains different phenomena affecting the sea level. Vu and Peng [5, 6] have showed that it is possible to relate the surges to SSL obtained by GNSS-R measurements. Moreover monitoring these surges allows to detect the extreme meteorological events such as tempests and hurricanes and the passage of any meteorological depression.

The goal of the present study is to extend the detection to the impact of barometric variations on the SSL in different conditions in coastal areas using GNSS-R technique. 


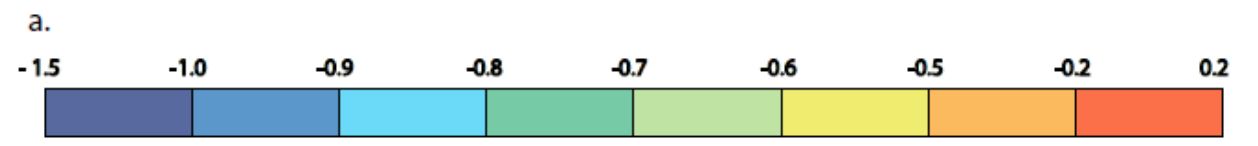

$\triangle$ Tide Gauge

- GNSS Antenna

- Specular reflection points (GPS)

- Specular reflection points (GLONASS)

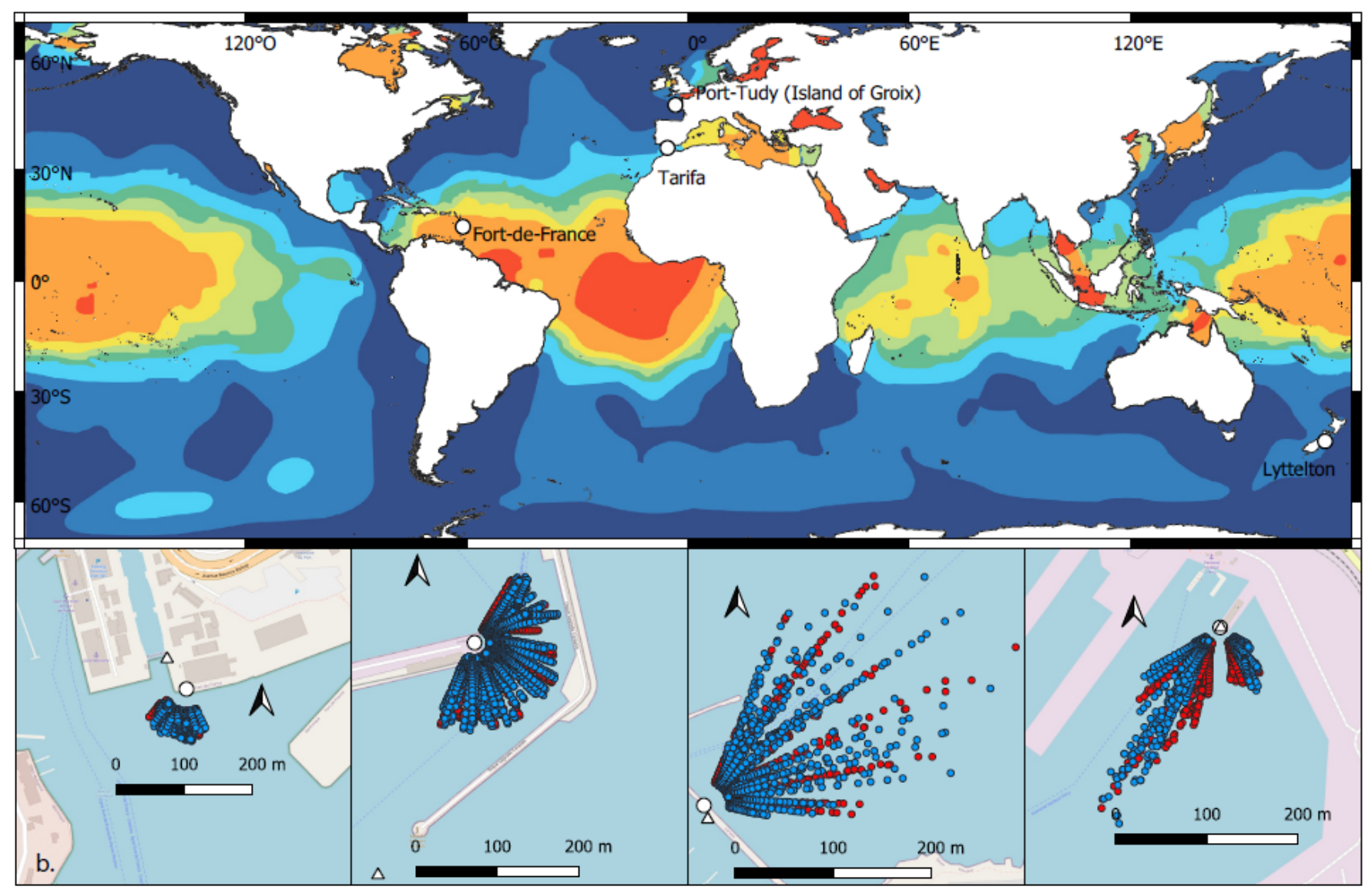

Fig. 1. (a) Sea level response to air pressure forcing (in $\mathrm{cm} / \mathrm{mbar}$ ) from [1] with the geographical locations of the stations used in the study (b) with a zoom on each GNSS stations (from left to right: Fort-de-France, Tarifa, Port-Tudy, Lyttelton)

\section{DATA}

The Figure 1 shows the location of the different sites that were exploited in this study. These stations from the existing national GNSS network were chosen in order to cover a wide range of latitude: the Port-Tudy station on the island of Groix in France and the Lyttelton station near Christchurch in NewZealand are in the temperate zone of relative medium latitude, at $47^{\circ} 38^{\prime} 40^{\prime \prime}$ North and $43^{\circ} 36^{\prime} 21^{\prime \prime}$ South respectively. The Tarifa station is located near the strait of Gibraltar at a lower latitude $\left(36^{\circ} 00^{\prime} 31^{\prime \prime}\right.$ North) that represents the border between the Atlantic Ocean and the Mediterranean Sea. Finally, the last station at Fort-de-France, is located in the island of Martinique, in the tropical band (14 $36^{\prime} 5^{\prime \prime}$ North). Most stations are protected from swells and the effects of wind to minimize their impact on SSL.

For each station, a couple of an antenna and a receiver provide GNSS data for several consecutive months to a year, a collocated tide gauge provides SLH measurements and the barometric data sets come from nearby meteorological stations (located at a maximum distance of $7.5 \mathrm{~km}$ from the GNSS antenna at Fort-de-France).

The data are sampled as follow: 30 seconds for the GNSS data, 1 minute for the tide gauges records (with the exception of Lyttelton with a sampling period of 1 hour) and 1 hour for the meteorological data (which include the barometric measurements).

\section{METHODOLOGY}

The GNSS data are processed with a Signal to Noise Ratiobased (SNR) technique that uses a single classical GNSS receiver and antenna. By considering the direct and reflected signals that arrives to the antenna, one can retrieve the height 


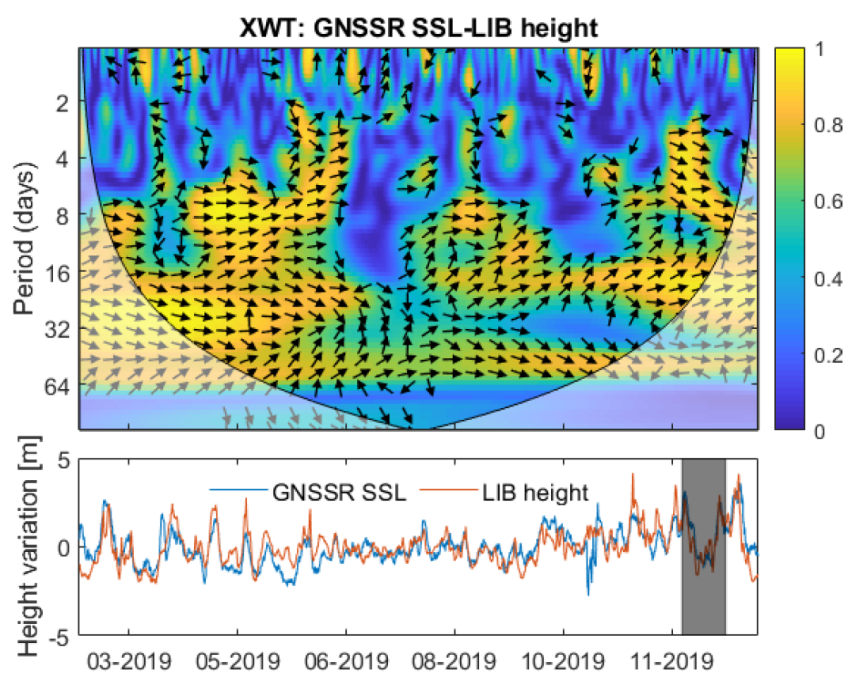

Fig. 2. Cross Wavelet Transforms (XWT) of the SSL and LIB (inversion of the meteorological pressure) height time series in the case of Port-Tudy and the associated profiles of both time series; The grey zone correspond to the period given Table 2

$h$ between the antenna and the reflection surface i.e. the sea surface. This reflected signal is recorded in the SNR data by the receiver under the form of undulations of an average frequency versus the sinus of the GNSS satellite elevation. Different methods for the determination of $h$ exist from SNR data following different approximations. For this study, a "dynamic SNR" method [4] will be used.

In order to retrieve the SLH properly via the GNSS-R, only the reflection points situated over the sea will be considered for each station (see Figure 1p). These locations of reflection are obtained geometrically using a simulator based on the precise ephemeris (SP3) of the GNSS satellite constellations and the position of the receiving antenna [7].

\section{RESULTS}

\subsection{GNSS-R derived sea level height}

The GNSS-R SLH measurements are directly compared to tide gauge records. Results show that both time series are in good agreement. Overall, the correlation between the two series reaches 0.9 and the RSME is of the order of a few decimeters, even centimeters in the case of Lyttelton i.e. $(0.07 \mathrm{~m})$.

These results are satisfying and they demonstrate the performance of the GNSS-R to observe the SLH at first order.

\subsection{Impact of the barometric variations}

For analyzing the impact of the barometric variations, first we need to remove tide effects. This task is achieved by the
T_Tide program developed by Rich Pawlowicz [8]. This program consists in a harmonic analysis based on known astronomical tide periods. The SSL is then isolated as the difference between the SLH measurements and the tide model.

This SSL is then compared to barometric variations which are converted to height variations through a coefficient of 1 $\mathrm{cm} / \mathrm{mbar}$. The direct correlation is computed at first hand but low correlation coefficients were found (see Table 1). Thus, a cross wavelet transform (XWT) based on a Morlet wavelet is applied following the method proposed by Grinsted [9]. This allows the detection of correlation versus both time and frequency between two time series. The result of this XWT for the station of Port-Tudy is shown in Figure 2.

This analysis reveals that the best correlations between the two series are found at period greater than several days.

Thus, a mean filter of varying size is applied to the SSL in order to isolate the low frequency component. The filter size is determined in order to maximize the direct correlation between the SSL and the LIB height for each station (see Table 1). Both the SSL and the LIB height profiles for the Port-Tudy location are plotted in Figure 2

\begin{tabular}{|l|ccc|}
\hline Station & $\begin{array}{c}\text { Size of the } \\
\text { filter }\end{array}$ & $\begin{array}{c}\text { Before } \\
\text { filtering }\end{array}$ & $\begin{array}{c}\text { After } \\
\text { filtering }\end{array}$ \\
\hline Port-Tudy & 2.2 & 0.31 & 0.67 \\
Lyttelton & 1.9 & 0.31 & 0.59 \\
Tarifa & 1.0 & 0.34 & 0.55 \\
Fort-de-France & 6.7 & 0.29 & 0.39 \\
\hline
\end{tabular}

Table 1. Direct correlation between the SSL and LIB height full time series before and after low-pass filtering along with the size of the filter applied (size in days)

A possible trend (correlation between 0.5 and 0.8 ) between the two time series after the application of the mean filter is observed. Correlation seems to be higher in both Lyttelton and Port-Tudy station than in Fort-de-France (close to equator) and Tarifa.

Moreover, for the Fort-de-France station, the improvement of correlation after applying the filter is not significant. We can also notice that the size of the filter which maximize this improvement is larger than for the other stations. We conclude that the impact of the LIB on sea surface in Fort-deFrance is less apparent than in the other stations on the global scale.

On the XWT maps (see Figure 2), high correlations appear on specific time events. The Table 2 shows the direct correlation between the time series during specific events with the optimal mean filter determined previously applied. For Fort-de-France where a mean filter of a size of 0.8 days was used in order to maximize the correlation on the specific event. These periods of good linear correlation (above 0.8) are linked to meteorological events such as the passage of the storm Dorian over the Martinique island or the occurrence of 
several major windstorms on the southern Europe near Tarifa and Port-Tudy stations during the 2019-2020 windstorm season.

These meteorological events imply great barometric variations, which lead to strong correlations between the response of the sea level and the LIB effect.

\begin{tabular}{|l|lc|}
\hline Station & Period & Correlation \\
\hline Port-Tudy & $25 / 11 / 19$ to $22 / 12 / 19$ & 0.88 \\
Lyttelton & $15 / 05 / 18$ to $15 / 07 / 18$ & 0.89 \\
Tarifa & $30 / 11 / 19$ to $28 / 12 / 18$ & 0.87 \\
Fort-de-France & $26 / 08 / 19$ to $29 / 08 / 19$ & 0.73 \\
\hline
\end{tabular}

Table 2. Correlation between SSL and LIB height during specific time periods characterized by the passage of important depressions

\section{DISCUSSION}

The analysis of the LIB effect in coastal zone shows different phenomena. First, most of the variation in sea level due to LIB is observed at period greater than 1-2 days. It agrees with previous studies that stated that the impact of the LIB varies with the period of observation [1]. It also agrees with the fact that the response of the sea level to LIB effect follows a dynamic behavior in coastal zone instead of an instantaneous behavior [2].

The LIB impact is less visible in Fort-de-France than in any other station partially due to weaker barometric variations at low latitude. However, in the tropical band, even if the depressions are smaller in size and in duration than the ones occurring in extra tropical band, their intensity is generally greater. We can observe one of these tropical storm in Fort-de-France during a short period of high correlation. It corresponds to the passage of a high intensity storm, Dorian (which will become a hurricane later). On the other side, for the three other stations the depressions are bigger in timescale which agrees with the higher correlation periods found.

An interesting perspective from these results is to change the mean filtering applied to the SSL to spectral analysis methods in order to discriminate in a more efficient way the LIB impact in the SSL time series and study more deeply the impact of the observation period.

\section{CONCLUSION}

This study showed clearly the feasibility of observations of subtidal phenomena through GNSS-R with the example of the LIB. Moreover, the different results show that the response of the sea level to the LIB effect is strongly dependent on different factors such as the latitude as well as the intensity and timescale of meteorological depression.

\section{REFERENCES}

[1] EL Mathers and PL Woodworth, "Departures from the local inverse barometer model observed in altimeter and tide gauge data and in a global barotropic numerical model," Journal of Geophysical Research: Oceans, vol. 106, no. C4, pp. 6957-6972, 2001.

[2] Philip L Woodworth, Angélique Melet, Marta Marcos, Richard D Ray, Guy Wöppelmann, Yoshi N Sasaki, Mauro Cirano, Angela Hibbert, John M Huthnance, Sebastià Monserrat, et al., "Forcing factors affecting sea level changes at the coast," Surveys in Geophysics, vol. 40, no. 6, pp. 1351-1397, 2019.

[3] F Geremia-Nievinski, T Hobiger, R Haas, W Liu, J Strandberg, S Tabibi, Sibylle Vey, J Wickert, and Shannon Williams, "Snr-based gnss reflectometry for coastal sea-level altimetry: results from the first iag intercomparison campaign," Journal of Geodesy, vol. 94, no. 8, pp. 1-15, 2020.

[4] Nicolas Roussel, Guillaume Ramillien, Frédéric Frappart, José Darrozes, Adrien Gay, Richard Biancale, Nicolas Striebig, Vincent Hanquiez, Xavier Bertin, and Damien Allain, "Sea level monitoring and sea state estimate using a single geodetic receiver," Remote sensing of Environment, vol. 171, pp. 261-277, 2015.

[5] Phuong Lan Vu, Minh Cuong Ha, Frédéric Frappart, José Darrozes, Guillaume Ramillien, Grégory Dufrechou, Pascal Gegout, Denis Morichon, and Philippe Bonneton, "Identifying 2010 xynthia storm signature in gnssr-based tide records," Remote Sensing, vol. 11, no. 7, pp. 782, 2019.

[6] Dongju Peng, Emma M Hill, Linlin Li, Adam D Switzer, and Kristine M Larson, "Application of gnss interferometric reflectometry for detecting storm surges," GPS Solutions, vol. 23, no. 2, pp. 47, 2019.

[7] N Roussel, F Frappart, G Ramillien, J Darrozes, C Desjardins, P Gegout, F Pérosanz, and R Biancale, "Simulations of direct and reflected wave trajectories for groundbased gnss-r experiments," Geoscientific Model Development, vol. 7, no. 5, pp. 2261-2279, 2014.

[8] Rich Pawlowicz, Bob Beardsley, and Steve Lentz, "Classical tidal harmonic analysis including error estimates in matlab using t_tide," Computers \& Geosciences, vol. 28, no. 8, pp. 929-937, 2002.

[9] Aslak Grinsted, John C Moore, and Svetlana Jevrejeva, "Application of the cross wavelet transform and wavelet coherence to geophysical time series," 2004. 